DOI: $10.17805 /$ zpu.2016.3.5

\title{
Культурное пространство территории как ресурс экономики впечатлений
}

\author{
В. В. НОВОСЕЛЬСКАЯ \\ (МИНИСТЕРСТВО КУЛЬТУРЫ РЕСПУБЛИКИ КРЫМ)
}

В статье рассматриваются основные аспекты и возможности экономики впечатлений в развитии территории посредством использования ее культурного потенциала. Предполагается, что механизмом сближения экономики и культуры является трансформация понятий «культурный ресурс» и «культурная ценность».

Понятие культурного пространства рассматривается через призму концепции экономической ценности и культурного ресурса Д. Тросби, где культура выступает «катализатором» возрождения определенной территории, создавая как прямую, так и косвенную экономическую ценность. В данном контексте проводится параллель между культурным потенциалом территории, ее устойчивым развитием и новой ролью культурного наследия, заключающейся в формировании и сохранение культурной и национальной идентичности, которое, кроме всего прочего, выступает определенным культурно-экономическим активом. Таким образом, культура понимается как капитал, являющийся источником культурных благ, ценностей и услуг, ресурсы которого невозможно полностью исчерпать.

Отмечается, что экономика впечатлений является современным продуктом развития культуры. Именно впечатления чаще всего являются основой культурных индустрий и сферы развлечений, сопровождая производство и потребление любого культурного продукта, они всегда личностны и строятся на узнавании или приобщении к чемуто величественному, например к культурному наследию, культурным ценностям той или иной территории, региона. Впечатления лежат в основе феномена, получившего название «бренд территории», так как являются «ядром» популярности того или иного места, города, региона или страны в целом. Предполагается, что в современном мире одной из функций территории стало производство впечатлений как фактора ее успешного не только культурного, но и экономического развития. Впечатления стоят дороже услуг, так как их ценность невозможно свести к экономической выгоде.

В исследовании приводятся примеры успешной продажи и использования впечатлений в своей деятельности отечественными и зарубежными культурными и туристическими объектами. Показывается ценность впечатлений как персонализируемого товара, отмечается, что именно они обеспечивают успех компаний и лежат в основе экономических, социальных и культурных стратегий территориального развития.

Ключевые слова: культура; культурный ресурс; культурный капитал; культурное наследие; экономика впечатлений; культурный туризм; развлечения; Д. Тросби

\section{ВВЕАЕНИЕ}

A ктуальность исследования проблемы развития территорий посредством использования их культурного потенциала обусловливается несколькими причинами. Во-первых, современная экономика, переместившая культуру с периферии в центр своих изысканий, подарила нам креативные индустрии, приносящие целому ряду развитых стран достаточно высокий доход, основанный на продаже впечатлений. Во-вторых, глобализационные процессы, охватившие современное общество, привели к появлению глокализации как попытки культур и народов сохранить собственную уникальность и неповторимость. Ее появление стало своеобразным ответом попыткам унифицировать современный мир, где производятся и тиражируются миллионы одинаковых товаров и услуг, который опутан инфор- 
мационными сетями, словно паутиной, где очень сложно, с одной стороны, чем-то удивить, а с другой - не потерять свою идентичность. Сегодня только культура способна справиться с этой задачей, традиции и ценности которой маркируют различия между людьми, народами и нациями.

В современных гуманитарных исследованиях в этом ключе все чаще звучит проблема культурного пространства, культурных ценностей и культурного наследия. Причем вопрос заключается не столько сугубо в его сохранении, сколько в необходимости его использования в качестве ресурса развития среды, основы для формирования своеобразного культурного бренда той или иной территории.

Проблема развития территории путем использования ее культурного потенциала объединяет сразу несколько направлений в современных научных исследованиях. Само понятие культурного потенциала тесно связано с культурным пространством - достаточно широким по смыслу термином, употребляемым как по отношению к культуре в целом, так и для характеристики конкретного феномена социально-культурной сферы. В таком ключе его, например, использует С. Иконникова, определяя культурное пространство как сферу повседневности, в которой сочетаются историческая преемственность, местный колорит и уникальные традиции регионов (Иконникова, 2005: 35). В настоящее время существует несколько контекстов определения данного феномена, от сугубо философских исследований Ю. Аотмана, М. Кагана и др. (Цотман, 1996; Каган, 1993) до географических и урбанистических концепций В. Каганского и В. Глазычева (Каганский, 2001; Глазычев, 2011).

Следует отметить тенденцию изучения культурного пространства в региональном срезе, прослеживающуюся в работах отечественных авторов. С точки зрения А. Мурзина, культурное пространство проявляется «в виде некой ментальной карты» (Мурзин, 2009: Электронный ресурс), на которой представлены прошлое страны, ее ценности и источники существования и развития.

Культурное пространство как синтез двух частей - пассивной части (культурного наследия) и активной части (культурного производства, участвующего в социально-экономических отношениях) рассматривается и в законодательстве Российской Федерации о культуре (Проект Федерального закона ... , 2011: Электронный ресурс).

Анализ взаимовлияния культурных ресурсов, к которым относится и культурное наследие, и развития среды находит свое отражение в концепциях А. Тросби, интерпретирующего культурное наследие как культурный капитал (Тросби, 2013), Ч. Цэндри, понимающего территорию как ресурс развития әкономики (Иэндри, 2011). Особо следует отметить работы Аж. Пайна и Аж. Гилмора, описавших возникновение впечатления как четвертого экономического предложения, напрямую зависящего от культурного потенциала территории (Пайн, Гилмор, 2005).

Среди отечественных исследователей, анализирующих тенденции и особенности сближения культуры и экономики, особенно выделяются работы А. Аолгина, посвященные оценке әффективности культуры с точки зрения новой, «символической», экономики (Аолгин, 2006, 2010), А. Рубинштейна и В. Музычук, рассматривающих основные проблемы эффективности культуры как объекта управления и участника экономических отношений, а также тенденции и влияние культуры на социально-экономическое развитие (Рубинштейн, 2012; Музычук, 2011, 2012). 
Прагматике культуры и ее вкладу в социальное и экономическое развитие территорий посвящены работы Т. Абанкиной и А. Рубинштейна (см.: Абанкина, 2005, 2015: Электронный ресурс; Экономика культуры, 2005). С культурологической точки зрения тему взаимосвязи культуры и развития как одну из центральных в проблематике ЮНЕСКО, рассматриваемую через призму проблем межкультурного диалога в культурной политике, регионального развития ресурсами культурных проектов развивает в своих статьях О. Астафьева (см.: Астафьева, 2013, 2014, 2015).

Предметом нашего рассмотрения в данной статье выступает культурное пространство территории в определенном ракурсе - как ресурс экономики впечатлений, а основной задачей - анализ основных аспектов экономики впечатлений, характерных для развития культурного потенциала территории.

\section{КУАБТУРНОЕ ПРОСТРАНСТВО КАК РЕСУРС}

$\mathrm{XX}$ век ознаменовал собой интенсивное повышение интереса к культуре с прагматической и утилитарной точек зрения. В исследованиях новых видов ресурсов, экономического потенциала, устойчивого развития территорий культура неизбежно занимает одно из первых мест, выступая источником и основой дальнейшего развития общества, причем не столько духовного, сколько экономического (см.: Вуд, 2004; Аэндри, 2011; Тросби, 2013). Представлениям об экономической ценности культуры предшествовало появление в XIX в. идей классиков рыночной экономики, многие из которых поднимали вопрос о рассмотрении окружающей среды как капитала, ее влиянии на производство товаров и услуг в экономике. Фактически складывалась концепция природного капитала, не только предшествовавшая появлению в экономике четвертого типа капитала - культурного, но и сближающая природные и материальные культурные ресурсы, называемые $A$. Тросби «культурными экосистемами», необходимыми для поддержания «культурной жизни и жизнеспособности человеческой цивилизации» (Тросби, 2013: 81).

Остановимся подробнее на механизмах сближения экономики и культуры, и в особенности на трансформации понятий «культурный ресурс» и «культурная ценность». C последним напрямую связано восприятие культуры как ограниченного пространства, ее территориальное измерение, легшее в основу регионального устойчивого развития. Ф. Бродель, рассматривая культуру как пространство с очерченными границами, в рамках которых и протекает вся социальная жизнь, в работе «Что такое Франция» определяет конкретные территории, такие как города, городки, предместья и села как культурные пространства, формирующие характерные культурные ценности, образы и смыслы, традиции и обычаи каждого конкретного региона (Бродель, 1994).

В настоящее время существует, как уже было сказано выше, множество подходов к определению культурного пространства, обобщив которые можно дать следующее определение данного феномена. Культурное пространство - это не только окультуривание природной среды и преобразование окружающей действительности, но и наделение территории особым смыслом, проявление ее уникальности и самобытности, воплощаемое в местных традициях, фольклоре, преданиях, обычаях, праздниках, продуктах как высокой, так и народной культуры, в исторических и этнокультурных памятниках. Оно включает экологическое, географиче- 
ское, социальное, политическое, психологическое пространства, информационные ресурсы, охватывает потребности и ценности человека, его способ мышления и образ жизни.

Аанное понятие в ключе экономической ценности и культурного ресурса рассматривается А. Тросби. Остановимся на нескольких важных аспектах, подчеркиваемых исследователем. Во-первых, культура - это не набор безжизненных артефактов, которые нужно охранять, культура - это ресурс и своеобразный «катализатор» возрождения территории. В работах «Роль культуры в әкономическом развитии» (Тросби, 2004) и «Экономика и культура» (Тросби, 2013) А. Тросби неоднократно подчеркивает все возрастающую роль культуры в региональном и городском развитии. Несмотря на то что основное внимание он уделяет городскому развитию, все эти положения характерны и для регионального развития в целом.

Культурный потенциал территории может проявляться в четырех направлениях, не исключающих, а чаще всего активно дополняющих друг друга.

1. Находящиеся в городе объекты культуры сами по себе могут являться символами, влияющими на экономику. Примеры - Пизанская башня или дворец Альгамбра в Гранаде.

2. Чаще возникает ситуация, когда развитию города способствует не один объект, а целый район ( «культурный округ»), как, например, в Аублине или Питтсбурге.

3. Жизненно важным компонентом городской экономики могут стать различные отрасли индустрии культуры (особенно здесь велико значение изобразительного искусства). Причем такое может иметь место не обязательно в мегаполисах типа Цондона или Нью-Йорка, но и в небольших городах и населенных пунктах.

4. Роль культуры может проявляться и в воспитании у граждан общего самосознания, творческого духа, сплоченности и жизненной активности (Тросби, 2004: 45).

Экономическая ценность данных культурных ресурсов имеет как прямые, так и косвенные составляющие. Аоходы от культурного ресурса (например, кинотеатров, музеев, галерей и т. п.) часто рассматриваются как прямой вклад в развитие территории. Однако косвенная составляющая, по словам А. Тросби, часто не принимаемая во внимание, бывает весьма значительной как в обеспечении занятости, так и в увеличении благосостояния территории. Под ней понимают отрасли, сопутствующие культуре, - транспорт, пищевая индустрия в лице ресторанного бизнеса, туристическая отрасль и т. п.

Во-вторых, в настоящее время в контексте развития территории все чаще употребляется понятие «культурная ценность» как фактор противостояния последствиям глобализационных процессов. Именно культурный ресурс территории в виде местных традиций, национальных обычаев, фольклора, объектов исторической и культурной памяти, особенностей изобразительного искусства, художественной и народной культуры позволяет оценить всю важность культурного многообразия и уникальности в глобализирующемся мире. В этом контексте интересна параллель между культурным потенциалом территории, ее устойчивым развитием и новой ролью культурного наследия. 


\section{РАЗВИТИЕ ТЕРРИТОРИИ И КУАБТУРНОЕ НАСАЕАИЕ}

Само понятие «культурное наследие» полисемантично и включает в самом широком смысле весь значимый унаследованный культурный опыт. По определению Конвенции ЮНЕСКО об охране всемирного культурного и природного наследия, принятой в 1972 г., «...под “культурным наследием” понимаются: палятники: произведения архитектуры, монументальной скульптуры и живописи, элементы или структуры археологического характера, надписи, пещеры и группы элементов, которые имеют выдающуюся универсальную ценность с точки зрения истории, искусства или науки; ансалбли: группы изолированных или объединенных строений, архитектура, единство или связь с пейзажем которых представляют выдающуюся универсальную ценность с точки зрения истории, искусства или науки; достопримечательные места: произведения человека или совместные творения человека и природы, а также зоны, включая археологические достопримечательные места, представляющие выдающуюся универсальную ценность с точки зрения истории, эстетики, этнологии или антропологии» (Конвенция об охране ... : Электронный ресурс).

В пункт 8 статьи 5 проекта Федерального закона «О культуре в Российской Федерации», находящегося на рассмотрении в Государственной Ауме, культурное наследие определяется как «...материальные и нематериальные объекты культуры, созданные в прошлом и представляющие ценность с эстетической, социальнокультурной, исторической, археологической, архитектурной и иных точек зрения, значимые для сохранения и развития культурной самобытности Российской Федерации, этнических и иных культурных сообществ, их вклада в мировую цивилизацию» (Проект Федерального закона ... , 2011: Электронный ресурс).

В настоящее время наблюдается изменение самой сути подхода к восприятию культурного наследия, и связано это с распространением концепции устойчивого развития с природной и экономической сфер, в том числе, и в сферу культуры. Так, наследие сейчас воспринимается не как совокупность культурных артефактов, главной задачей в отношении которых является их сохранение как исторической ценности для будущих поколений. В современных условиях развития его основной функцией является формирование и сохранение культурной и национальной идентичности, оно «...выступает в качестве фактора поддержания стабильности в отдельно взятом регионе и мире в целом» (Сибирцева, Кильдяшова, 2011: 120).

Именно культурное наследие формирует, в том числе, и культурное пространство территории как сферу распространения «определенных устойчивых ценностей, традиций и верований, обеспечивающих существование и развитие культуры и обладающих преемственностью» (Проект Федерального закона ... , 2011: Электронный ресурс), о чем речь шла выше. Понимание культуры как необходимого фактора устойчивого развития территории не только расширило функции культурного наследия, но и сформировало его восприятие в качестве определенного культурно-экономического актива.

Так, определение устойчивого развития, данное Всемирной комиссией по окружающей среде и развитию, как удовлетворяющего «...потребности настоящего, не ущемляя способность будущих поколений удовлетворять свои потребности» (цит. 
по: Тросби, 2013: 83), вполне применимо и к культуре, понимаемой сегодня как капитал, являющийся источником культурных благ, ценностей и услуг.

Как было сказано выше, многие артефакты и нематериальные проявления культуры сегодня считаются культурными активами, и ценность именно культурного капитала как особого, четвертого его вида, вслед за известными исследователями, такими как П. Бурдье и А. Тросби, фиксируется и законодательно, на уровне федеральных законов и международных конвенций. Так, например, упомянутый проект Федерального закона «О культуре в Российской Федерации», в отличие от действующего закона «Основы законодательства Российской Федерации о культуре» (утв. ВС РФ 09.10.1992 № 3612-1), учитывает, в том числе, и экономический потенциал культуры.

Ценность культурного капитала заключается не только в невозможности исчерпать и потребить весь культурный ресурс (в отличие от природного, например), но и в том, что культурный капитал, в отличие от «обычного», создает и культурную, и экономическую ценность. Это применимо к культурному капиталу практически без изменений. Еще в 1776 г. А. Смит первым обратил внимание на «ценность товара в потреблении, т. е. способность удовлетворять потребности человека, и ценность при обмене, т. е. количество других товаров и услуг, с которыми кто-то готов расстаться, чтобы приобрести единицу товара» (цит. по: Тросби, 2013: 39). В данной связи интересна мысль А. Тросби о том, что «...социальный капитал исчерпывается не при использовании, а при отсутствии использования» (там же: 78).

В этом аспекте потребление культуры выглядит еще более привлекательным, ведь с культурой расстаться практически невозможно, как «используя» ее при производстве других товаров и услуг, так и неограниченно ее потребляя. Это качество культуры, равно как и ее уникальность, легли в основу принципа функционирования особого типа современной экономики - «экономики впечатлений».

\section{ЭКОНОМИКА ВПЕЧАТ АЕНИЙ: \\ «ВЕСЬ МИР - ТЕАТР , А КУАБТУРА - ЭТО АЕКОРАЦИИ}

Суть данной концепции, разработанной гарвардскими экономистами Аж. Пайном и Аж. Гилмором, заключается в появлении нового, наиболее востребованного, а следовательно, наиболее продаваемого и популярного продукта - вnечаmления. В работе, название которой представляет собой перефразированное изречение В. Шекспира «Экономика впечатлений. Работа - это театр, а каждьй бизнес - сцена» (Пайн, Гилмор, 2005), описаны появление и особенности нового экономического феномена, порождаемого культурой и составляющего конкуренцию уже привычным для потребителей товарам и услугам.

По сути, впечатление представляет собой четвертое экономическое предложение, идущее после сырья, товара и услуги и предлагающее потребителю продукт в виде незабываемых ощущений и чувств. Именно они чаще всего являются основой культурных индустрий и сферы развлечений, сопровождая производство и потребление любого культурного продукта, будь то шоу, концерты, театр, кино, выставки и т. п. Впечатления личностны, они строятся на узнавании или приобщении к чему-то величественному, например к культурному наследию, культурным цен- 
ностям той или иной территории, региона. Именно впечатления лежат в основе достаточно популярного в настоящее время феномена, получившего название «бренд территории», так как являются «ядром» популярности того или иного места, города, региона или страны в целом. Примером этому может служить такая знаменитая фраза - «Увидеть Париж и умереть», суть которой как раз и заключается в признании уникальности и неповторимости данного места как некоего естественного бренда - узнаваемого образа территории как ресурса его развития и способа привлечения инвестиций.

В современном мире одной из функций территории стало производство впечатлений как фактора ее успешного не только культурного, но и экономического развития. Аж. Пайн и Аж. Гилмор описывают такую роль культурного пространства как ресурса в своем знаменитом примере: «Стоимость двух одинаковых чашек кофе различается в разы, если одну из них выпить в обычной столовой, а другую в кафе на площади Сан-Марко в Венеции. В первом случае продается только сам продукт, во втором случае продается не просто кофе, но впечатление - вид на площадь и ощущение сопричастности великому городу» (там же: 44).

Остановимся подробнее на том, что же такое впечатления и каковы их особенности. Авторы выделяют четыре вида экономических предложений потребителю - сырье, товар, услуга и впечатление. Сырье - это «материалы природного происхождения» (там же: 9). Если применить данную концепцию к развитию культурного потенциала конкретной территории, например Крыма, то можно провести следующую аналогию. Весь природный ландшафт, включающий море, горы, климат и т. п., в данном случае можно воспринимать как сырье. В этом плане, например, поездка в Крым «дикарями» воспринимается как покупка сырья: где каждый отдельно получает походы в горы, купание на море, поиск подходящего жилья и т. п., причем потребитель в данном случае стремится приобрести все это с наибольшей выгодой, так как, «покупая» море, он покупает только возможность искупаться. В таком контексте сырье мало отличимо от товара, что подчеркивают и Аж. Пайн с Аж. Гилмором. Товары - это «стандартизированная продукция, которую компания производит, а затем инвентаризует» (там же: 10). Существенную роль в различии цен здесь играют сопутствующие траты на производство и качество. В качестве примера приведем Сочи и Крым, где сырье, т. е. Черное море, одно и то же, а различия коренятся в логистике и сопутствующих тратах, из которых и складывается цена, например, на единый билет.

Ао недавнего времени максимумом, который производители могли предложить потребителям, были услуги. Ао сих пор некоторые экономисты придерживаются мнения, что впечатления являются частью сферы услуг и не заслуживают отдельного внимания как со стороны исследователей, так и со стороны бизнеса. Аж. Пайн и Аж. Гилмор определяют услуги как нематериальную деятельность, направленную на «...удовлетворение потребностей данного клиента» (там же: 11). Услуги ценятся выше, чем товары, и тем более сырье, хотя, предоставляя их, поставщики используют все те же товары. Это связано с тем, что товары просто предоставляют человеку возможность самостоятельно удовлетворить нужные потребности, а услуги освобождают человека от такой необходимости, являясь, как уже было сказано выше, процессом удовлетворения этих потребностей. Так, исследователи приводят такой пример: в США испеченный пирог является не- 
отъемлемым и главным атрибутом каждого празднования детского дня рождения. Ао середины XX в. приготовление пирога было обязанностью мамы, покупавшей ингредиенты (сырье), стоившие около 20-30 центов. Позже стали появляться компании (Procter\&Gamble и пр.), специализирующиеся на производстве полуфабрикатов - упаковок с нужным количеством ингредиентов, необходимых для выпечки одного пирога. Стоили они немного дороже - около 1-2 долларов (что значительно дороже сырья), однако были очень популярны и заменили собой продажу просто сырья по нескольким причинам - они превосходили их по вкусовым качествам, экономили время, упрощали процесс приготовления и позволяли не покупать лишние продукты. С 80-х годов ХХ в. на данный сегмент рынка проникли услуги по выпечке пирогов на любой вкус и кошелек - их можно было заказать в ближайшей булочной или супермаркете, и праздничные пироги в американских семьях перестали печь самостоятельно. Эти услуги стоили на порядок выше, чем полуфабрикаты, - около 10-20 долларов, однако с успехом покупались многими семьями. Причина заключалась в значительной экономии сил и времени, и потребители считали, что такая услуга является «прекрасной покупкой». Начало XXI в. ознаменовало собой появление компаний, не только предоставляющих услуги по выпечке пирогов, но и берущих на себя организацию таких мероприятий «под ключ». Стоимость такого мероприятия увеличивается еще на порядок по сравнению с услугой (от 100 до 250 долларов), однако их популярность все возрастает, так как главный продукт, продаваемый такими компаниями, - это незабываемые, уникальные впечатления: «На седьмой день рождения Элизабет семья Пайн отправилась на старую ферму, где именинница и ее четырнадцать друзей увидели, что собой представляет аграрная экономика. Они чистили коров, пасли овец, кормили цыплят, делали яблочный сок, собирали сено и катались по полю и лесу. <..>> Современные городские дети настолько далеки от аграрной экономики, что для них само пребывание на ферме становится впечатлением! Постановка подобных впечатлений станет следующим шагом в сельскохозяйственном маркетинге» (там же: 21).

Как видно из данного примера, услуги и впечатления значительно отличаются друг от друга, так как услугам все же присуща стандартизация в отличие от персонализированных, направленных на каждую личность впечатлений.

Наилучшей характеристикой впечатлений является фраза, приведенная авторами вышеупомянутой книги: «Самые лучшие вещи на земле - не вещи» (там же: 20). Экономя на товарах и услугах, люди вряд ли захотят экономить на впечатлениях, затрагивающих «глубинные струны их души». Одной их характеристик впечатления является их понимание как незабываемых театрализованных действий, где покупатели становятся гостями, а производители и продавцы - режиссерами и актерами, предлагающими не просто товар или услугу, а «...так или иначе связанные с ними впечатления, которые вызывают у клиента широкую гамму чувств. Все предыдущие экономические предложения не проникали во внутренний мир покупателя, в то время как впечатления по сути своей личностны. Они затрагивают человека на эмоциональном, физическом, интеллектуальном или даже на духовном уровне. Нет двух людей, которые получили бы одинаковые впечатления. Каждое впечатление возникает как следствие “соприкасания” поставленного действа и состояния человека» (там же: 13-14). 
Впечатления стоят дороже услуг, так как их ценность невозможно свести к экономической выгоде, их нельзя потрогать или увидеть, однако можно забрать с собой навсегда. По словам А. Аолгина, «люди стремятся к счастью; с чем бы они ни связывали и как бы ни понимали это состояние, оно в значительной мере реализуется через эмоциональную и творческую активность... а выразить ее потребители способны посредством постфактумных денежных сигналов. Эти платежи будут указывать на реализованную полезность произведения, или его воспринимаемое качество, или качество символических коммуникаций, а еще можно сказать качественное личностное время... которое сам человек определил как хорошо проведенное» (Аолгин, 2006: 361-362). И именно впечатления являются индикатором этого качества, увеличивая ценность эмоций и переживаний, которые непосредственно их дарят, и потребность в которых возрастает с каждым днем вследствие процессов унификации и стандартизации, охвативших современное общество. Как подчеркивает А. Аолгин, «людям нужны не эмоции вообще, нужны эмоции определенного типа в конкретное время» (Аолгин, 2002: Электронный ресурс).

Пока впечатления ценятся так высоко на интуитивном уровне, однако их ликвидность уже доказана успехами компаний, их производящих и продающих. На этом строятся стратегии креативных индустрий, и в частности шоу-бизнеса и спорта: «...мировой бокс лелеет десяток суперзвезд, чьи вознаграждения за матч превышают 5-10 миллионов долларов. Аоходы остальных в сотни раз меньше. Причина различий в ликвидности: при участии “звезды” вероятность драмы на порядок выше. Аудитория во всем мире согласна платить, чтобы избежать разочарования. Она права, ведь это ресурс свободного времени, ресурс внимания, которого не так уж много» (там же).

В итоге такое свойство культуры, как полезность, лежащее в основе впечатлений, приобретает особую экономическую, психологическую и социальную ценность. Еще один феномен, на который следует отдельно обратить внимание, - это развлечения. Они являются самым известным и старейшим видом впечатлений, и сегодня производство последних напрямую связано с новой индустрией, получившей название «индустрия развлечений». Развлекательный элемент проникает в настоящее время практически в каждый сегмент жизни общества.

Так, Аж. Пайн и Аж. Гилмор приводят такой пример из области туризма: одна из компаний, издающих туристические путеводители, опубликовала книгу «Записки беглеца», посвященную описанию двадцати восьми способов погрузится в незабываемые впечатления во время путешествий (Пайн, Гилмор, 2005: 17). Специализированные магазины, сотрудничающие с этой компанией, не только продают товары, которые необходимы для описанных приключений, но и само посещение магазина покупателями превратили в незабываемое развлечение: «Bass Pto Shops переносит элементы окружающей среды в интерьер магазина, в REI была воздвигнута гора высотой пятьдесят пять футов для того, чтобы покупатели смогли проверить альпинистское снаряжение, а в магазине Cabela's была установлена диорама - гора высотой 35 футов, на склонах которой расположены чучела диких животных» (там же).

Впечатления, создаваемые для увеличения объема продаж, рано или поздно, по словам Е. Петренко, сами становятся основным товаром (Петренко, 2009: Электронный ресурс). Ярким отечественным примером продажи впечатлений является 
сафари-парк «Тайган», расположенный в г. Белогорске Республики Крым. Цена билета в данный зоопарк на порядок выше цены посещения любого другого зоопарка. Все дело в необычных впечатлениях, уникальных и неповторимых эмоциях от приключений и возможностей наблюдать животных в естественной для них среде, что недоступно для среднестатистического современного человека, а потому крайне ценно. Помимо получения собственной прибыли, данный объект является катализатором развития экономического и культурного потенциала территории, на которой он расположен, и все это - за счет продажи впечатлений.

Ааже традиционные культурные институты, такие как музеи, галереи, театры и т. п., определенные британскими экспертами как ресурс для деятельности креативных индустрий, сейчас активно используют впечатления в своей деятельности. Е. Аебедева, российский специалист в области PR-технологий, приводит пример удачного использования впечатлений при организации выставки в Голландии: «Некоторое время назад в Амстердаме в здании Новой церкви проходила выставка “Богатство Строгановых. История одной русской семьи". Рекламные анонсы в СМИ настойчиво внедряли в сознание голландцев две мысли: Строгановы - самый состоятельный после царя род в России, и второе - именно Строгановы изобрели знаменитое блюдо бефстроганов, отведать которое можно тут же в ресторане Новой церкви. Расчет был сделан очень точно: Голландия - страна бюргерская, с высокоразвитой культурой “хорошо посидеть”. Аа и бренд “самого богатого после царя" интриговал воображение. В итоге в выходные дни на выставку стояла примерно получасовая очередь» (Аебедева, 2003: Электронный ресурс).

Использование самого культурного наследия как ресурса производства впечатлений и развития территории хорошо иллюстрирует пример культурного и экономического преображения малых городов (Мышкин, Тихвин, Старицы, Коломны и др.), где удалось переломить ситуацию «вымирания культуры», привлечь туристические потоки. В ориентации системы управления на активное участие населения в развитии среды посредством реализации социально ориентированных культурных проектов видится будущее в социально-экономическом развитии локальных поселений (Астафьева, Горушкина, 2010: 111).

Также следует отметить современные тенденции привлечения культуры к программам территориального развития в некоторых субъектах Российской Федерации. Как отмечает Н. Кочеляева, анализируя планирование в сфере культуры, изложенное в четырех стратегиях развития данной отрасли, само понимание культуры вышло за пределы «узковедомственной направленности» и включает историко-культурное наследие, культурные потребности населения, культурные блага и ресурсы, культурный бренд региона и т. п. (Кочеляева, 2015: 208). Тенденции, имеющие место в культурной политике Российской Федерации, по словам Н. Кочеляевой, не только способствуют формированию «комфортной культурной среды как важнейшего социального института» (там же: 207), но и позволяют все чаще воспринимать сферу культуры в качестве полноправного сектора экономики. Вовлечение нематериальных активов культуры в процессы социальных, экономических, технологических и экологических перемен выступают приоритетными направлениями территориального развития, поскольку позитивно влияют на повышение качества жизни и инвестиционную привлекательность региона (там же: 207). 
В этой связи можно обратить внимание на саму отрасль культуры, и в частности мероприятия, проводимые «классическими» музеями. Так, например, в Симферопольском художественном музее с 2012 г. каждый декабрь проходит благотворительный Рождественский Таврический Бал, во время которого не только воссоздается историческая обстановка, но и проводятся аукционы, вырученные средства с которых направляются как на реализацию детских воспитательнообразовательных программ, так и на ремонт и поддержание внешнего облика самого музея. Все приведенные примеры иллюстрируют постепенно открываемые возможности использования культурного потенциала для успешного развития территории.

\section{ЗАКАЮЧЕНИЕ}

Итак, довольно часто, говоря о культуре той или иной территории, ограничиваются стандартным перечислением музеев, театров и иных культурных институтов, составляющих культурное наследие данного региона, которое нуждается только в охране и спонсорской поддержке, при этом совершенно упуская из виду их экономический потенциал. И именно концепция «экономики впечатлений», предложенная Аж. Пайном и Аж. Гилмором, раскрыла возможности использования уникальности и неповторимости культуры. Потребность во впечатлениях стала одной из самых востребованных в современном обществе, для представителей которого важны всегда новые эмоции, даже от одного и того же события дибо места. Эта особенность связана с механизмом потребления культуры, описанным А. Аолгиным: человек всегда ждет новых впечатлений от прочитанной книги, просмотренного фильма или спектакля, даже если ее содержание ему давно знакомо. Это же применимо и к посещению одних и тех же мест, и именно на этом основана индустрия культурного туризма - мы всегда получаем качественно новые впечатления по сравнению с предыдущими, и качественно разные по отношению к впечатлениям других. Это связано как с феноменами, порождаемыми нашим сознанием, - с переживанием, восприятием и т. А., так и с особенностями культурных ценностей, которые только выигрывают от их потребления. Именно это делает впечатления самым востребованным и дорогим «товаром» современности.

\section{СПИСОК АИТЕРАТУРЫ}

Абанкина, Т. В. (2005) Экономика желаний в современной «цивилизации досуга // Отечественные записки: журнал для медленного чтения. № 4 (25). С. 115-123.

Абанкина, Т. В. (2015) Глобальный город. Власть, деньги и творчество [Электронный peсурс] // Искусство кино. № 2. URL: http://kinoart.ru/archive/2015/02/globalnyj-gorodvlast-dengi-i-tvorchestvo (дата обращения: 05.06.2016).

Астафьева, О. Н., Горушкина, С. Н. (2010) Инфраструктура культуры локальных территорий и место проектной деятельности в ее развитии // Местные сообщества: проблемы социокультурного развития : сб. науч. ст. / под ред. Ю. М. Резника, Н. И. Мироновой. М. : Независимый институт гражданского общества. 192 с. С. 102-118.

Астафьева, О. Н. (2013) Аинамика социокультурных процессов // Культура устойчивого развития: от идеи к реальности / сост. и науч. ред. Н. М. Мамедов. Баку : Элм. 348 с. C. 53-66.

Астафьева, О. Н. (2014) Стратегия устойчивого развития в культурной политике российских регионов // Образование, наука, культура в современном мире: материалы Меж- 
дународной научной веб-конференции «Базовые идеи ЮНЕСКО в современном образовании, культуре и науке» (Москва, март 2013 г.) / отв. ред. В. К. Егоров. М. : Пашков Аом. 423 c. C. $48-62$.

Астафьева, О. Н. (2015) Развитие диалоговых моделей ЮНЕСКО и их включение в стратегии культурной политики // Образование, культура, наука и коммуникации в современном мире: материалы Второй международной научной веб-конференции «ЮНЕСКО и новые идеи в современном образовании, культуре, науке, информации и коммуникации» / отв. ред. В. К. Егоров. М. : Пашков Аом. 409 с. С. 227-243.

Бродель, Ф. (1994) Что такое Франция : в 2 кн. М. : ИзА-во им. Сабашниковых. Кн. 1. 406 c.

Вуд, Ф. (2004) Творческая экономика городов // Экология культуры: Инф. бюллетень. Архангельск. № 2. С. 17-23.

Глазычев, В. А. (2011) Город без границ. М. : Территория будущего. 400 с.

Аолгин, А. Б. (2002) Прагматика культуры [Электронный ресурс] // Философсколитературный журнал Могос. № 2. URL: http://www.ruthenia.ru/logos/number/2002_02/ 06.htm (дата обращения: 25.05.2016).

Аолгин, А. Б. (2006) Экономика символического обмена. М. : Инфра-М. 632 с.

Аолгин, А. Б. (2010) Манифест новой экономики. Вторая невидимая рука рынка. М. : ACT. 256 c.

Иконникова, С. Н. (2005) История культурологических теорий. СПб. : Питер. 474 с.

Каган, М. С. (1993) Пространство и время как культурологические категории // Вестник СПбГУ. Сер. 6. Вып. 4. С. 30-40.

Каганский, В. А. (2001) Культурный ландшафт и советское обитаемое пространство : сб. ст. М. : Новое литературное обозрение. 576 с.

Конвенция об охране всемирного культурного и природного наследия [Электронный ресурс]// UNESCO. URL: http://whc.unesco.org/archive/convention-ru.pdf (дата обращения: 19.05.2016).

Кочеляева, Н. А. (2015) Стратегическое планирование в сфере культуры: российский опыт региональной культурной политики // Ярославский педагогический вестник. № 2. T. I (Культурология). С. 206-211.

Мебедева, Е. (2003) Стратегии продвижения культурного продукта [Электронный ресурс] // Журнал «60 параллель». № 2 (9). URL: http://journal.60parallel.org/ru/journal/ 2003/4/16.html (дата обращения: 10.06.2016).

Аотман, Ю. М. (1996) Внутри мыслящих миров. Человек - текст - семиосфера - история. М. : Языки русской культуры. 464 с.

Иэндри, Ч. (2011) Креативный город : пер. с англ. М. : Издательский дом «КлассикаXXI». 399 c.

Музычук, В. Ю. (2011) Культурный императив социально-экономического развития // Справочник руководителя учреждения культуры. № 4. С. 69-77.

Музычук, В. Ю. (2012) Аолжно ли государство финансировать культуру? М. : Институт экономики РАН. 60 с.

Мурзин, А. Э. (2009) Российское культурное пространство в региональном измерении: поиск новой интегративной модели [Электронный ресурс] // Стратегия России. № 1. URL: http://sr.fondedin.ru/new/fullnews_arch_to.php?subaction=showfull\&id=1232712514\& archive $=1232714081 \&$ start_from $=\& u c a t=14$ (дата обращения: 12.06.2016).

Пайн, Аж., Гилмор, Аж. (2005) Экономика впечатлений: работа — это театр, а каждый бизнес - сцена : пер. с англ. М. : Вильямс. 304 с.

Петренко, Е. С. (2009) Экономика впечатлений выведет рестораны из кризиса [Электронный ресурс] // Креативная экономика. № 3 (27). С. 132-138. URL: http://www.creativeconomy.ru/articles/2231/ (дата обращения: 23.05.2016). 
Проект Федерального закона «О культуре в Российской Федерации» (2011) [Электронный ресурс]// Российская газета. 26 октября. URL: http://rg.ru/2011/10/26/kulturasite-dok.html (дата обращения: 15.05.2016).

Рубинштейн, А. Я. (2012) Вступительная заметка // Журнал Новой экономической ассоциации. № 2 (14). С. 126-127.

Сибирцева, Ю. А., Кильдяшова, Т. А. (2011) Культурные ресурсы территории: стратегия развития // Вестник Северного (Арктического) федерального университета. Сер. Гуманитарные и социальные науки. № 2. С. 120-124.

Тросби, А. (2004) Роль культуры в экономическом развитии // Государственная служба за рубежом. Управление культурой. Реферативный бюллетень. № 5 (55). М. : Изд-во РАГС. С. 39-49.

Тросби, А. (2013) Экономика и культура : пер. с англ. М. : Изд. дом Высшей школы экономики. 256 с.

Экономика культуры (2005) / отв. ред. А. Я. Рубинштейн. М. : ИзА-во «Слово/Slovo». $605 \mathrm{c}$.

Aата поступления: 15.06 .2016 2.

\section{CULTURAL SPACE AS A RESOURCE OF EXPERIENCE ECONOMY \\ V. V. NOVOSELSKAYA \\ (Ministry of Culture, Republic of Crimea)}

The article investigates the main features and opportunities provided by experience economy for the development of a territory by making use of its cultural resources. It is suggested that the path to mutual convergence of economy and culture lies in the transformation of the notions of 'cultural resource' and 'cultural value'.

Our understanding of cultural space has been informed by the concepts of economic value of cultural resource as developed by D. Throsby. He believes that culture acts as a 'catalyst' in the process of territorial regeneration by creating both direct and indirect economic value. In our context, we draw a parallel between a territory's cultural resource, its sustainable development and the new role played by the cultural heritage. This role involves shaping and preserving cultural and national identity which can be viewed as both cultural and economic asset. Thus culture is construed as capital, as an inexhaustible source of cultural goods, services and values.

It has been noted that experience economy itself is a product of contemporary culture. It is unique experience that most frequently forms the foundation of cultural industries and the world of entertainment. They accompany the production and consumption of any cultural product; they are always personalized and involve recognizing or partaking of some exalted entity, i.e. cultural heritage or values shared by people of a certain area or region. It is experience that helps shape "a territorial brand', as it is the 'core' popularity factor of a locality, city, region or country. In the contemporary world, one of the functions of a territory is producing experience as a factor of both economic and cultural development. Experience is more expensive than service, since it cannot be reduced to sheer economic gain.

Our study explores some examples of successful supply and use of experience in the work of both Russian and foreign tourist sites. By emphasizing the value of experience as a customizable commodity, we show that they play a crucial role in the company's success and underpin the economic, social and cultural strategies of territorial development.

Keywords: culture; cultural resource; cultural capital; cultural heritage; experience economy; cultural tourism; entertainments; D. Throsby 


\section{REFERENCES}

Abankina, T. V. (2005) Ekonomika zhelanii v sovremennoi «tsivilizatsii dosuga». Otechestvennye zapiski, no. 4 (25), pp. 115-123. (In Russ.).

Abankina, T. V. (2015) Global'nyi gorod. Vlast', den'gi i tvorchestvo. Iskusstvo kino, no. 2 [online] Available at: http://kinoart.ru/archive/2015/02/globalnyj-gorod-vlast-dengi-itvorchestvo (access date: 05.06.2016). (In Russ.).

Astaf'eva, O. N. and Gorushkina, S. N. (2010) Infrastruktura kul'tury lokal'nykh territorii i mesto proektnoi deiatel'nosti v ee razvitii. In: Mestnye soobshchestva: problemy sotsiokul'turnogo razvitiia: sb. nauch. st., Iu. M. Reznik and N. I. Mironova (eds.). Moscow, Nezavisimyi institut grazhdanskogo obshchestva. 192 p. Pp. 102-118. (In Russ.).

Astaf'eva, O. N. (2013) Dinamika sotsiokul'turnykh protsessov. In: Kul'tura ustoichivogo razvitiia: ot idei k real'nosti, comp., ed. N. M. Mamedov. Baku, Elm. 348 p. Pp. 53-66. (In Russ.).

Astaf'eva, O. N. (2014) Strategiia ustoichivogo razvitiia v kul'turnoi politike rossiiskikh regionov. In: Obrazovanie, nauka, kul'tura v sovremennom mire: materialy Mezhdunarodnoi nauchnoi veb-konferentsii «Bazovye idei I NESKO v sovremennom obrazovanii, kul' ture i nauke» (Moskva, mart 2013 g.), ed. V. K. Egorov. Moscow, Pashkov Dom. 423 p. Pp. 48-62. (In Russ.).

Astaf'eva, O. N. (2015) Razvitie dialogovykh modelei IuNESKO i ikh vkliuchenie v strategii kul'turnoi politiki. In: Obrazovanie, kul'tura, nauka i kommunikatsii v sovremennom mire: materialy Vtoroi mezhdunarodnoi nauchnoi veb-konferentsii "I INESKO $i$ novye idei v sovremennom obrazovanii, kul'ture, nauke, informatsii $i$ kommunikatsii», ed. V. K. Egorov. Moscow, Pashkov Dom. 409 p. Pp. 227-243. (In Russ.).

Brodel, F. (1994) Chto takoe Frantsiia : in 2 books. Moscow, Izd-vo im. Sabashnikovykh. Book 1. 406 p. (In Russ.).

Wood, Ph. (2004) Tvorcheskaia ekonomika gorodov. In: Ekologiia kul'tury: Inf. biulleten'. Arkhangel'sk. No. 2, pp. 17-23. (In Russ.).

Glazychev, V. L. (2011) Gorod bez granits. Moscow, Territoriia budushchego. 400 p. (In Russ.).

Dolgin, A. B. (2002) Pragmatika kul'tury. Logos, no. 2 [online] Available at: http://www. ruthenia.ru/logos/number/2002_02/06.htm (access date: 25.05.2016). (In Russ.).

Dolgin, A. B. (2006) Ekonomika simvolicheskogo obmena. Moscow, Infra-M. 632 p. (In Russ.).

Dolgin, A. B. (2010) Manifest novoi ekonomiki. Vtoraia nevidimaia ruka rynka. Moscow, AST. 256 p. (In Russ.).

Ikonnikova, S. N. (2005) Istoriia kul'turologicheskikb teorii. St. Petersburg, Piter. 474 p. (In Russ.).

Kagan, M. S. (1993) Prostranstvo i vremia kak kul'turologicheskie kategorii. Vestnik SPbGU, issue 6, vol. 4, pp. 30-40. (In Russ.).

Kaganskii, V. L. (2001) Kul' turnyi landshaft $i$ sovetskoe obitaemoe prostranstvo : sb. st. Moscow, Novoe literaturnoe obozrenie. 576 p. (In Russ.).

Konventsiia ob okhrane vsemirnogo kul'turnogo i prirodnogo naslediia. UNESCO [online] Available at: http://whc.unesco.org/archive/convention-ru.pdf (access date: 19.05.2016). (In Russ.).

Kocheliaeva, N. A. (2015) Strategicheskoe planirovanie v sfere kul'tury: rossiiskii opyt regional'noi kul'turnoi politiki. Iaroslavskii pedagogicheskii vestnik, no. 2, vol. I (Kul'turologiia), pp. 206-211. (In Russ.).

Lebedeva, E. (2003) Strategii prodvizheniia kul'turnogo produkta. Zhurnal «60 parallel' », no. 2 (9), [online] Available at: http://journal.60parallel.org/ru/journal/2003/4/16.html (access date: 10.06.2016). (In Russ.). 
Lotman, Yu. M. (1996) Vnutri mysliashchikb mirov. Chelovek - tekst - semiosfera istoriia. Moscow, Iazyki russkoi kul'tury. 464 p. (In Russ.).

Landri, Ch. (2011) Kreativnyi gorod. Moscow, Izdatel'skii dom «Klassika-XXI». 399 p. (In Russ.).

Muzychuk, V. Yu. (2011) Kul'turnyi imperativ sotsial'no-ekonomicheskogo razvitiia. Spravochnik rukovoditelia ucbrezbdeniia kul'tury, no. 4, pp. 69-77. (In Russ.).

Muzychuk, V. Yu. (2012) Dolzhno li gosudarstvo finansirovat' kul'turu? Moscow, Institut ekonomiki RAN. 60 p. (In Russ.).

Murzin, A. E. (2009) Rossiiskoe kul'turnoe prostranstvo v regional'nom izmerenii: poisk novoi integrativnoi modeli. Strategiia Rossii, no. 1 [online] Available at: http://sr.fondedin.ru/new/fullnews_arch_to.php?subaction=showfull\&id=1232712514\&archive $=1232714081$ \&start_from $=\& u c a t=14$ (access date: 12.06.2016). (In Russ.).

Pine, J. and Gilmore, J. (2005) Ekonomika vpechatlenii: rabota - eto teatr, a kazbdyi biznes - stsena. Moscow, Vil'iams. 304 p. (In Russ.).

Petrenko, E. S. (2009) Ekonomika vpechatlenii vyvedet restorany iz krizisa. Kreativnaia ekonomika, no. 3 (27), pp. 132-138 [online] Available at: http://www.creativeconomy.ru/articles/2231/ (access date: 23.05.2016). (In Russ.).

Proekt Federal'nogo zakona «O kul'ture v Rossiiskoi Federatsii» (2011). Rossiiskaia gazeta, October 26 [online] Available at: http://rg.ru/2011/10/26/kultura-site-dok.html (access date: 15.05.2016). (In Russ.).

Rubinshtein, A. Ya. (2012) Vstupitel'naia zametka. Zhurnal Novoi ekonomicheskoi assotsiatsii, no. 2 (14), pp. 126-127. (In Russ.).

Sibirtseva, Yu. A., Kil'diashova, T. A. (2011) Kul'turnye resursy territorii: strategiia razvitiia. Vestnik Severnogo (Arkticheskogo) federal'nogo universiteta, Ser. Gumanitarnye i sotsial'nye nauki, no. 2, pp. 120-124.

Throsby, D. (2004) Rol' kul'tury v ekonomicheskom razvitii. In: Gosudarstvennaia sluzhba za rubezhom. Upravlenie kul'turoi. Referativnyi biulleten', no. 5 (55). Moscow, RAGS Publ. Pp. 39-49. (In Russ.).

Throsby, D. (2013) Ekonomika i kul'tura. Moscow, Izd. dom Vysshei shkoly ekonomiki. 256 p. (In Russ.).

Ekonomika kul'tury (2005), ed. A. Ya. Rubinshtein. Moscow, Izd-vo «Slovo/Slovo». 605 p. (In Russ.).

Submission date: 15.06 .2016$.

Новосельская Вера Вадимовна - кандидат педагогических наук, министр культуры Республики Крым. Адрес: 295000, Россия, г. Симферополь, пр. Кирова, д. 13, каб. 316. Тел.: +7 (3652) 276-657; 276-657. Эл. aspec: mincult@rk.gov.ru

Novoselskaya Vera Vadimovna, Candidate of Pedagogy, Minister of Culture, Republic of Crimea. Postal address: Office 316, 13 Kirov Ave., 295000 Simferopol, Republic of Crimea, Russian Federation. Tel.: +7 (3652) 276-657. E-mail: mincult@rk.gov.ru 